\title{
Characterization of the key aroma compounds in three types of bagels by means of the sensomics approach
}

\author{
Ola Lasekan ${ }^{1 *}$, Fatma Dabaj ${ }^{1}$, Megala Muniandy ${ }^{1}$, Nurul Hanisah Juhari ${ }^{2}$ and Adeseye Lasekan ${ }^{3}$
}

\begin{abstract}
Background: To evaluate the impact of cold fermentation time on bagel rolls, the key aroma-active compounds in the volatile fractions obtained from three different bagel rolls through solvent assisted flavor evaporation (SAFE) were sequentially characterized by an aroma extract dilution analysis (AEDA), quantified by stable isotope dilution and analyzed by odor activity values (OAVs) respectively.

Results: Findings revealed 40 aroma-active compounds with flavor dilution (FD) factor ranges of 2-1024. Of these, 22 compounds ( $F D \geq 16$ ) were quantified by stable isotope dilution assays (SIDA). Subsequent analysis of the 22 compounds by odor activity values (OAVs) revealed 14 compounds with $\mathrm{OAVs} \geq 1$ and the highest concentrations were obtained for 2,3-butanedione, 2-phenylethanol, 3-methylbutanal and acetoin respectively. Two recombination models of the bagels (i.e. $24 \mathrm{~h}$ and $48 \mathrm{~h}$ bagels) showed similarity to the corresponding bagels. Omission tests confirmed that 2,3-butanedione (buttery), acetoin (buttery), 2-acetyl-1-pyrroline (roasty), 5-methyl-2-furanmethanol (bread-like), (Z)-4-heptenal (biscuit-like) and 4-hydroxy-2,5-dimethyl-3(2H)-furanone, were the key aroma compounds. Additionally, acetic acid, butanoic acid, 2-phenylethanol (honey-like), 3-methylbutanoic acid, 2/3-methylbutanal, vanillin, 3-methylbutanol, methional were also important odorants of the bagel.
\end{abstract}

Conclusion: Whilst the long, cold fermented bagels exhibited roasty, malty, buttery, baked potato-like, smoky and biscuit-like notes, the control bagels produced similar but less intense odor notes.

Keywords: Bagel, Aroma-active compounds, Cold fermentation, Sensomics approach

\section{Introduction}

Bagels are one of the most widely consumed bread rolls in the United States. Recent statistics have shown that 204 million Americans consumed bagels in 2019 [1]. This figure is projected to increase to 210 million in 2023 [1]. Bagels have a very simple formulation similar to simple bread or roll formulas (i.e. flour, salt, yeast, and water). However, what differentiates bagel from the rest of the rolls are the flour quality and the long, cold fermentation

\footnotetext{
*Correspondence: olaniny56@gmail.com

${ }^{1}$ Department of Food Technology, University Putra Malaysia, UPM,

43400 Serdang, Malaysia

Full list of author information is available at the end of the article
}

of the dough used in bagel production. Traditional bagels are often produced with high protein (13-16\%) spring wheat flour [2]. In addition, the long, cold fermentation step called retardation gives the traditional bagels a distinctive crust and flavor not found in the regular bread rolls. The quality of bread is normally defined by its volume, texture, color and flavor [3]. However, the aroma of bread is undoubtedly one of the most important qualities that influence its acceptance by consumers [4].

Bread flavor appreciation is one of the first evaluation signals encountered by consumers during bread consumption [5]. The flavor of bread is engendered by the interaction of a large number of compounds, which exhibit different olfactive characteristics, tactile oral and 
trigeminal sensations. Some of these compounds include; alcohols, aldehydes, esters, ketones, acids, hydrocarbons, pyrazines, pyrrolines, furans etc. [3, 4]. Over 300 volatile compounds have been reported in white bread [6]. In addition, the odour quality of bread depends on many factors like; type of flour, type of fermentation [7] and dough improvers [8] used during bread production. The production process and storage are also known to influence the flavor of bread [9].

Analysis of volatile compounds in a food matrix is quite complex and several extraction methods have been reported, ranging from solvent extraction [10], headspace solid phase micro-extraction (HS-SPME) [11], dynamic headspace extraction (DHE) [4], multiple headspace solid phase micro-extraction (MH-SPME) [12], solvent assisted flavor evaporation (SAFE) [13] and vacuum sublimation [14]. In the same vein, many identification techniques have been employed to provide aroma profiles for different types of breads. Some of the techniques involved the use of gas chromatography-mass spectrometry alone [15] or coupled with a comprehensive bi-dimensional gas chromatography-time of flight mass spectrometry (GC $\times$ GC-TOFMS) [16], electronic nose [17], artificial mouth [18]. And proton-transfer-reaction mass spectrometry (PTR-MS) [19], which only provides the chemical identities of breads.

Recently, the sensomics approach, which includes, gas chromatography-olfactometry (GC-O), sensory analysis, aroma extraction dilution analysis (AEDA), identification experiments, quantitation by stable isotope dilution assays (SIDAs), calculation of odour activity values (OAVs) and aroma recombination and omission tests to validate analytical data, has proven a useful method for characterizing the potent aroma constituents of food [20]. Sensomics is a multi-step analytical procedure used for identifying and quantifying key odorants in a food matrix as well as defining their sensory impact on the overall food aroma [21, 22]. Sensomics approaches help to identify potent aroma compounds as well as taste components in food [23]. Furthermore, the sensomic approach combines separation-based chromatographic methods with reconstitution and omission experiments to evaluate the role of specific compounds in the perceived aroma of a mixture addition. The implication of this that the sensomics approach is able to produce a flavor-cum taste signatures of food [24]. In addition, the sensomics approach has been applied in the characterization of aroma compounds in yeast dough dumpling [22] and the crust of soft pretzels [25].

Although there are many reported studies on the characteristic aroma profiles of different wheat breads, however, there has been no reported study on bagels. In addition, bagel processing is slightly different from that of regular bread. Therefore, elucidating the flavor chemistry of bagels could improve their quality control and processing of bagels. The objective of this study was to characterize the key aroma compounds in long, cold fermented bagels using the sensomics approach.

\section{Materials and methods \\ Bagel production}

Bagel doughs were made by employing three processes differing in their cold fermentation conditions, and the time required for boiling the bagel dough in water (Fig. 1). The dough recipes contained high protein wheat flour 13\% (enriched bakers patent flour from Pastry Product Sdn., Malaysia) (2000 g); cold water, 1100 g; instant dry yeast, 30 g; salt, 30 g; granulated sugar, 60 g, shortening; $60 \mathrm{~g}$ and malt flour (high diastatic malted barley flour 185 Lintner minimum) $60 \mathrm{~g}$. The ingredients were made into dough by mixing it for $3 \mathrm{~min}$ in a mixer (Model VCM-44A-1, Stephan, Hameln, Germany). The dough was subsequently divided into 3 equal parts (dough A, B \& C). Dough A (control) was kneaded for $10 \mathrm{~min}$ and allowed to develop for about $1 \mathrm{~h}$. After $1 \mathrm{~h}$, the dough was further kneaded a dozen times and divided into eight pieces. Each dough piece was rolled into a rope and the two ends were joined together to form a circle with a diameter of approximately 1-2 inches. The bagels were dropped into a large boiling water pot and allowed to boil for 2 min with constant turning. The boiled bagels were baked in a pre-heated oven at $218{ }^{\circ} \mathrm{C}$ for $20 \mathrm{~min}$. Dough $\mathrm{B}$ was kneaded $(10 \mathrm{~min})$ as in dough $\mathrm{A}$ and allowed to develop for $1 \mathrm{~h}$. After the kneading operation, the dough mass was returned into a large bowl, covered tightly and kept in a chiller $\left(5^{\circ} \mathrm{C}\right)$ for $48 \mathrm{~h}$. After, $48 \mathrm{~h}$ of cold fermentation, the dough was brought out and kneaded for about $3 \mathrm{~min}$ and it was divided into eight pieces and made into eight bagels as described above. The bagels were boiled in water for $2 \mathrm{~min}$ and later baked in a pre-heated oven at $218{ }^{\circ} \mathrm{C}$ for $20 \mathrm{~min}$. Dough $\mathrm{C}$ was kneaded as in dough A and allowed to develop for $1 \mathrm{~h}$. After the kneading, the dough was divided into eight bagels. The pre-formed bagels were kept in the chiller $\left(5^{\circ} \mathrm{C}\right)$ for $24 \mathrm{~h}$. After $24 \mathrm{~h}$, the bagels were subjected to the same boiling and baking protocols as described above.

\section{Chemicals}

Pure chemical standards with purity ranging between 97 and $99 \%$ were used. The chemical standards included; acetic acid, butanoic acid, benzyl alcohol, 2,3-butanedione (diacetyl), heptanoic acid, 3-hydroxy-2-butanone (acetoin), and octanoic acid which were purchased from Merck (Darmstadt, Germany). Ethyl nonanoate, ethyl octanoate, 4-hydroxy-2,5-dimethyl-3(2H)-furanone (HDMF), (E)-2-nonenal, 2-phenyl ethanol, phenyl 

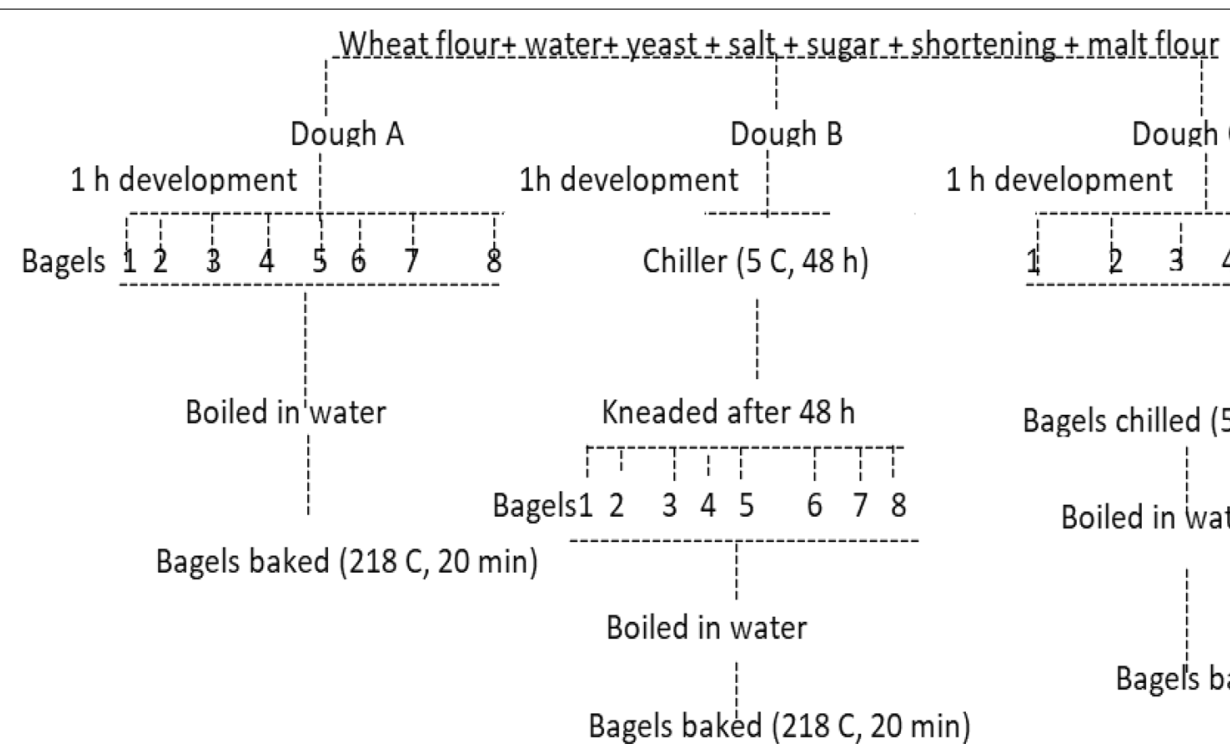

$1 \mathrm{~h}$ development

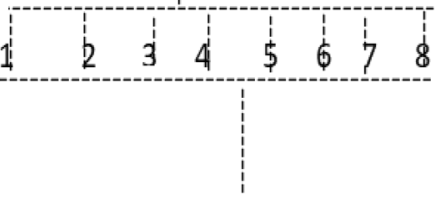

Bagels chilled $(5 \mathrm{C}, 24 \mathrm{~h})$

Boiled in water

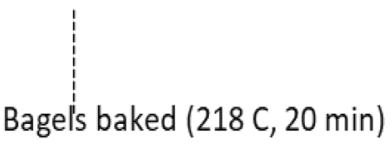

Fig. 1 Flow diagram for the production of bagels

acetaldehyde, 3-methylbutanoic acid, 3-methylbutanol, vanillin, 1-butanol, propionic acid, hexanoic acid, benzaldehyde, (E,E)-2,4-decadienal, furfural, 2-methylbutanal, 2,3-hexanedione, 2-heptanone, 5-methyl-2-furanmethanol, decanol, 4,5-epoxy-(E)-2-decanal, 1-octen-3-one, methional, 2-acetyl-1-pyrolline, sodium citrate dehydrate, and citric acid were from Aldrich (Steinheim, Germany) and 4-vinyl-2-methoxyphenol was purchased from
Lancaster (Eastgate, Morecombe, UK). Ethanol (40\% v/v) was of food grade. The following labelled compounds (Table 1) were synthesized according to the literature cited; $\left[{ }^{2} \mathrm{H}_{2}\right]$-butanoic acid [26]; 2-[ $\left[{ }^{2} \mathrm{H}_{2}\right]$-phenylethanol [27]; 3-[ $\left[{ }^{2} \mathrm{H}_{2}\right]$-methylbutanol [27]; $\left[{ }^{2} \mathrm{H}_{2}\right]$-ethyl octanoate [27]; $\left[{ }^{13} \mathrm{C}_{2}\right]$-acetic acid [28]; 3- $\left[{ }^{2} \mathrm{H}_{2}\right]$-methylbutanal [29]; $\left[{ }^{2} \mathrm{H}_{2}\right]$-2-acetyl-1-pyrroline [30]; $\left[{ }^{13} \mathrm{C}_{4}\right]$-2,3-butanedione [31]; $\left[{ }^{2} \mathrm{H}_{2}\right]-3$-methylbutanoic acid [32]; $\left[{ }^{13} \mathrm{C}_{6}\right]$-2-methoxy

Table 1 Selected ions, and calibration factors used for the quantification of aroma compounds in three bagels by stable isotope dilution assays

\begin{tabular}{|c|c|c|c|c|c|}
\hline No. & Compounds ${ }^{\mathrm{a}}$ & Selected ions (m/z) & Internal standards & Selected ions (m/z) & $\begin{array}{l}\text { Calibration } \\
\text { factor }^{\mathrm{b}}\end{array}$ \\
\hline 1 & Phenylethanol & 105 & $2-\left[{ }^{2} \mathrm{H}\right]$ phenylethanol & 107 & 1.02 \\
\hline 2 & Butanoic acid & 89 & {$\left[{ }^{2} \mathrm{H}\right]$ butanoic acid } & 91 & 0.89 \\
\hline 3 & 3-Methylbutanol & 71 & $3\left[{ }^{2} \mathrm{H}\right]$ methylbutanol & 73 & 0.87 \\
\hline 4 & Acetic acid & 61 & {$\left[{ }^{13} \mathrm{C}_{2}\right]$ acetic acid } & 63 & 1.00 \\
\hline 5 & Ethyl octanoate & 173 & {$\left[{ }^{2} \mathrm{H}\right]$ ethyl octanoate } & 176 & 1.00 \\
\hline 6 & $\begin{array}{l}\text { 4-Hydroxy-2,5-dimethyl-3(2H)- } \\
\text { furanone }\end{array}$ & 129 & $\begin{array}{l}\text { 4-Hydroxy-2 }\left[{ }^{13} \mathrm{C}\right] \text { methyl-5-methyl-3(2H)- } \\
\text { furanone }\end{array}$ & 131 & 1.00 \\
\hline 7 & 2,3-Butanedione & 87 & {$\left[{ }^{13} \mathrm{C}_{4}\right]-2,3$-butanedione } & 91 & 0.90 \\
\hline 8 & 3-Methylbutanal & 87 & {$\left[{ }^{2} \mathrm{H}\right]-3-$ methylbutanal } & 89 & 1.00 \\
\hline 9 & 3-Methylbutanoic acid & 60 & {$\left[{ }^{2} \mathrm{H}\right]-3$-methylbutanoic acid } & 62 & 1.00 \\
\hline 10 & Methional & 105 & {$\left[{ }^{2} \mathrm{H}\right]$-methional } & 108 & 1.00 \\
\hline 11 & 2-Acetyl-1-pyrroline & 112 & {$\left[{ }^{2} \mathrm{H}\right]$-2-acetyl-1-pyrroline } & 114 & 1.00 \\
\hline 12 & Phenylacetaldehyde & 121 & {$\left[{ }^{2} \mathrm{H}\right]$-2-phenylacetaldehde } & 123 & 0.85 \\
\hline 13 & 2-Methoxy-4-vinylphenol & 150 & {$\left[{ }^{13} \mathrm{C}_{6}\right]-2$-methoxy-4-vinylphenol } & 156 & 0.85 \\
\hline 14 & Vanillin & 137 & {$\left[{ }^{2} \mathrm{H}\right]$-vanillin } & 139 & 0.98 \\
\hline 15 & (Z)-4-Heptenal & 95 & {$\left[{ }^{2} \mathrm{H}\right]-(\mathrm{Z})$-4-heptenal } & 97 & 0.98 \\
\hline
\end{tabular}

Calibration factors ${ }^{\mathrm{b}}$ and compounds ${ }^{\mathrm{a}}$ were determined as earlier reported by Guth and Grosch [32] and Lasekan et al. [41] respectively 
vinyl phenol [33]; $\left[{ }^{2} \mathrm{H}\right]$-vanillin [33]; $\left[{ }^{2} \mathrm{H}_{2}\right]$-phenyl acetaldehyde [34]; $\left[{ }^{2} \mathrm{H}_{2}\right]$-heptenal [35] and 4-hydroxy-2 $\left[{ }^{13} \mathrm{H}_{2}\right]$ methyl-5-methyl-3(2H)-furanone [36]. Citrate buffer (0.1 M, pH 6.0) was prepared as follow: sodium citrate dehydrate $(12.044 \mathrm{~g}, 0.04 \mathrm{M})$ was added to $800 \mathrm{~mL}$ of distilled water in a liter round bottom flask with constant stirring. Subsequently, citric acid (11.341 g, $0.06 \mathrm{M})$ was added to the solution and the solution was adjusted to a pH 6.0 with $0.1 \mathrm{~N} \mathrm{HCl}$.

\section{Isolation of volatile constituents}

Freshly baked bagels were sliced into pieces, frozen in liquid nitrogen and pulverized in a Waring blender. The pulverized bagel $(300 \mathrm{~g})$ was extracted with dichloromethane $(700 \mathrm{~mL})$ at room temperature $\left(29^{\circ} \mathrm{C}\right)$ for $2 \mathrm{~h}$ and the obtained extract was subjected to solvent-assisted flavor extraction (SAFE) distillation [13] at $40{ }^{\circ} \mathrm{C}$. To separate the acidic volatiles from the neutral-basic fraction, the extract was treated four times with $50 \mathrm{~mL}$ of $0.5 \mathrm{~mol} \mathrm{~L}^{-1}$ aqueous sodium bicarbonate. The combined aqueous solutions were adjusted to $\mathrm{pH} 2$ with $\mathrm{HCl}\left(2 \mathrm{~mol} \mathrm{~L}^{-1}\right)$ and extracted with $50 \mathrm{~mL}$ of dichloromethane $(4 \times)$ to obtain the acidic fractions. Subsequently, the solutions (i.e. the acidic or the neutral-basic) were concentrated to $2 \mathrm{~mL}$ at $40{ }^{\circ} \mathrm{C}$ using a small size Vigreux column [37]. The concentrated extract was further concentrated to $200 \mu \mathrm{L}$ [38]. All analyses were repeated in triplicate.

\section{Analysis of volatile constituents}

The GC-MS was performed by means of a gas chromatograph type QP-5050A (Shimadzu, Kyoto, Japan) using the following capillary columns: DB-5 $(30 \mathrm{~m} \times 0.25 \mathrm{~mm}$ I.D; $0.25 \mu \mathrm{m}$ film thickness; Scientific Instrument Services, Inc., Ringoes, NJ); DB-FFAP (30 m, $0.32 \mathrm{~mm}$ I.D; $0.25 \mu \mathrm{m}$ film thickness, Scientific Instrument Services, Inc., Ringoes, NJ). The extracts $(2 \mu \mathrm{L})$ were applied by the on-column injection technique at $230{ }^{\circ} \mathrm{C}$. The temperature of the oven was raised at $40{ }^{\circ} \mathrm{C} \min ^{-1}$ to $50{ }^{\circ} \mathrm{C}$, held for $2 \mathrm{~min}$ isothermally and then raised at $4{ }^{\circ} \mathrm{C} \mathrm{min}^{-1}$ to $250{ }^{\circ} \mathrm{C}$. The flow rate of the carrier helium

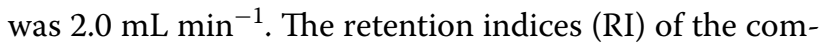
pounds were calculated as described previously [37].

Mass spectra were recorded in the electron impact positive mode (EI) over a scan ranges of $\mathrm{m} / \mathrm{z}$ 40-270 (scan frequency $5.8 \mathrm{~Hz}$ ) applying electron energy of $70 \mathrm{eV}$. Total run time was $45 \mathrm{~min}$. Source and transfer line temperatures were 200 and $240^{\circ} \mathrm{C}$ respectively. Mass spectra were evaluated by using the Xcalibur software (Thermos Scientific, Dreieich, Germany).

\section{GC-olfactometry}

To further identify the aroma constituents in the bagel extracts, an olfactory detection port ODP-3 (Gerstel,
Mulheim, Germany) connected to a Trace Ultra 1300 gas chromatograph (Thermos Scientific, Waltham, MA, USA) was used. The GC-O system was fitted with a DB-FFAP column $(30 \mathrm{~m} \times 0.32 \mathrm{~mm}$ i.d; film thickness, $0.25 \mu \mathrm{m}$, Scientific Instrument Services, Inc., Ringoes, $\mathrm{NJ})$. The $\mathrm{GC}-\mathrm{O}$ conditions are the same as reported in "Analysis of volatile constituents" section. The effluent was split 1:1. Sniffing was conducted as described previously [39]. Three experienced panelists (two females and a male) with strong gustative and olfactory responses in earlier sessions were used for the sniffing test. The sniffing analysis was divided into three sessions of $20 \mathrm{~min}$ and each assessor participated in the exercise. All analyses were repeated in triplicate by each assessor.

\section{Aroma extracts dilution analysis (AEDA)}

The flavor dilution (FD) factors of the aroma compounds were determined by $\mathrm{GC}-\mathrm{O}$ as reported by Lasekan and Yap [39]. The original extracts $(200 \mu \mathrm{L})$ containing the neutral/basic as well as the acidic volatile compounds obtained from the crumbs (300 g) were diluted in a stepwise fashion by the addition of dichloromethane as described earlier [39]. Three panelists evaluated all dilutions in triplicate. Only the aroma compounds detected by more than two panelists were recorded. The flavor dilution factors obtained by AEDA [40] were plotted against the retention index values of the corresponding aroma compound (FD chromatogram).

\section{Aroma compound quantification by stable isotope dilution assays (ACQSIDA)}

Labelled standards $(20-50 \mu \mathrm{g})$ previously dissolved in dichloromethane $(5 \mathrm{~mL})$ were added to each crumb $(100 \mathrm{~g})$. The obtained extract was subjected to SAFE distillation as described earlier in "Isolation of volatile constituents". Aliquots $(0.5 \mu \mathrm{L})$ of the concentrates were analyzed by means of two dimensional GC-MS as described previously [41]. Calibration factor for each compound was determined by analyzing mixtures of defined quantity of the labelled compounds in five different mass ratios $(1: 5,1: 3,1: 1,3: 1$, and 5:1) using the GC-MS. The obtained response factors from the peak area and the amounts of labelled compound are shown in Table 1 . The concentration of compounds quantified by the selected stable isotopologues is reported in Table 3.

\section{Orthonasal aroma analysis of bagel}

One hour after baking, the bagels (approximately $8 \mathrm{~g}$ with similar crust covering) were placed inside glass beakers (height $7 \mathrm{~cm}$, volume $45 \mathrm{~mL}$ ) with three random digitals and were orthonasally evaluated by panel members at room temperature $\left(29 \pm 2{ }^{\circ} \mathrm{C}\right)$. In addition, samples were rotated among panelists to prevent carry-over effects. 
The panel consisted of 10 members, aged between 24 and 35 years and were made up of seven women and three men. These panelists have participated in a weekly sensory training session for at least a year to be able to recognize and describe different aroma qualities. The sensory analyses were conducted in a sensory room following the International Standard (ISO 8589, 2007) [42] protocols with individual booths equipped with uniform and glare free white light (D65). Descriptors used were determined in preliminary sensory experiments as described by Steinhaus et al. [43]. The panelists started with seven descriptors and when all panelists were able to achieve complete agreement on a descriptor such a descriptor was chosen. Each descriptor used was defined on the basis of the odour of the selected aqueous solution of reference compounds. The reference compounds used as stimuli were; $10 \mu \mathrm{g} \mathrm{L}^{-1}$ of 2-acetyl-1-pyrroline (roasty); $100 \mu \mathrm{g} \mathrm{L}{ }^{-1}$ of 3-methylbutanal (malty); $70 \mu \mathrm{g} \mathrm{L}^{-1}$ of 2,3-butanedione (buttery); $50 \mu \mathrm{g} \mathrm{L}^{-1}$ of (Z)-4-heptenal (biscuit-like); $10 \mu \mathrm{g} \mathrm{L}^{-1}$ of 4-vinyl-2-methoxyphenol (smoky); $100 \mu \mathrm{g} \mathrm{L}^{-1}$ of methional (baked potato-like). During evaluation, the panelists had 5 min to rest after each set of samples was tested. All samples were repeated in triplicate. The intensities of the attributes were rated on a 7 -point linear scale (i.e. $0,0.5,1.0,1.5,2.0,2.5,3.0$ ) from 0 (not perceivable) to 3 (strongly perceivable) in steps of 0.5 by the panelists. The sensory data were analyzed by one-way analysis of variance (ANOVA) using SPSS 20.0 (SPSS Inc., Chicago, IL., USA). ANOVA with Duncan's multiple comparison tests were performed to determine whether there were differences among individual samples. The differences were considered to be significant at $\mathrm{p}<0.05$ (Table 4). In addition, the ethical standards as instituted by the institutional and/or national research committee according to the 1964 Helsinki declaration and its later amendments or comparable ethical Standards on studies involving human subjects were adhered to. The study protocol and consent procedure received ethical approval from the Institutional Review Board (IRB) of the University Putra Malaysia. Informed consent was obtained from all individual participants included in the study.

\section{Aroma model recombinant of the 24 and $48 \mathrm{~h}$ bagels}

Reference standards of key aroma compounds (Table 5) were prepared in ethanolic solution [44]. The combined ethanolic stock solutions of the 17 aroma compounds made up of 15 compounds with OAVs $>1$ and two compounds (i.e. acetic acid and acetoin) with significantly high concentrations (Table 5) $(500 \mu \mathrm{L})$ was added to citrate buffer $\left(30 \mathrm{~mL} ; \mathrm{pH} 5.6 ; 0.1 \mathrm{~mol} \mathrm{~L}^{-1}\right)$ and free corn starch $(30 \mathrm{~g})$ respectively in a closed Teflon cup. The Teflon cup was stirred continuously for $15 \mathrm{~min}$ at room temperature $29{ }^{\circ} \mathrm{C}$. The aroma model was evaluated orthonasally in comparison with the 24 and $48 \mathrm{~h}$ bagels as described above ("Orthonasal aroma analysis of bagel" section).

\section{Omission experiments}

A triangle test was performed to determine the significance of one odorant on the aroma recombination models ( $24 \mathrm{~h}$ and $48 \mathrm{~h}$ ) reported in Table 5 . For each of the models a glass of the mixture $(20 \mathrm{~mL})$ was prepared by omitting one or a group of selected odorants from the complete recombination model (Table 6). This mixture and two other glasses containing the complete recombination models were presented to the sensory panel in a triangle test [45]. The results of the Triangle tests were analyzed by comparing the total number of correct responses with the minimum number of responses required for statistical significance (ISO, 4120, 2004) [46]. Panel performance was obtained by applying analysis of variance (ANOVA) to the sensory profile data. The data were analyzed using SAS Statistical software (SAS Institute, Inc. 1996). The significance $\alpha$ was calculated according to the method of Callejo et al. [45]

\section{Results and discussion Identification of aroma-active compounds in control bagels}

A combined total of 40 aroma compounds were identified in the three differently processed bagels (i.e. control; $24 \mathrm{~h}$ cold fermented bagels: and bagels produced from $48 \mathrm{~h}$ cold fermented dough mass). Among these compounds, 10 aldehydes, 9 alcohols, 7 acids, 6 ketones, 5 heterocyclic compounds and 3 esters were positively identified (Table 2). To reveal the differences between the flavors of the bagels, the volatile fractions of their crumbs were subjected to AEDA. In the control bagels, 40 aroma compounds were detected in the FD factor range of 2 to 256 respectively (Table 2). Furthermore, the results revealed 2-acetyl-1-pyrroline (roasty), methional (baked potatolike), vanillin (vanilla-like), 2,3-butanedione (buttery) and 4-hydroxy-2,5-dimethyl-3(2H)-furanone (HDMF) as compounds with the highest FD values in the control bagel. These aroma-active compounds exhibited high FD factors (128-256) (Fig. 1). Other important aroma compounds in the control bagels were butanoic acid (sweaty), acetoin (buttery), benzaldehyde (almond-like), furfural (bread-like), 2/3-methyl butanoic acid (sweaty), acetyl pyrazine (toasty), phenyl acetaldehyde (honey-like), 2-phenylethanol (honey-like), octanoic acid (fatty, soapy), 4-vinyl-2-methoxyphenol (smoky), acetic acid (sour), 3-methyl butanol (malty), and 2-methylpyrazine (nutty) all of which exhibited FD factors ranging from 16 to 32 (Fig. 2). 
Table 2 Aroma compounds identified in cold fermented and control bagels

\begin{tabular}{|c|c|c|c|c|c|c|c|c|c|}
\hline No. & Compound $^{\mathrm{a}}$ & $\begin{array}{l}\text { Retention } \\
\text { index on } \\
\text { DB-5 }\end{array}$ & $\begin{array}{l}\text { Retention } \\
\text { index on } \\
\text { FFAP }\end{array}$ & Odour description ${ }^{b}$ & Fractions & $\begin{array}{l}F D \\
C B\end{array}$ & $\begin{array}{l}\mathrm{FD} \\
\mathrm{BF}_{24}\end{array}$ & $\begin{array}{l}\mathrm{FD} \\
\mathrm{BF}_{48}\end{array}$ & Identification method \\
\hline 1 & Acetic acid & 605 & 1443 & Sweaty & A & 32 & 64 & 64 & MS/RI/O/ST \\
\hline 2 & 2,3-Butanedione (diacetyl) & 606 & 993 & Buttery & NB & 128 & 512 & 1024 & $\mathrm{MS} / \mathrm{RI} / \mathrm{O} / \mathrm{ST}$ \\
\hline 3 & 1-Butanol & 636 & 1179 & Sweaty/buttery & NB & 4 & 4 & 8 & MS/RI/O/ST \\
\hline 4 & 2/3-Methylbutanal & 647 & 936 & Malty & NB & 8 & 16 & 16 & $\mathrm{MS} / \mathrm{RI} / \mathrm{O} / \mathrm{ST}$ \\
\hline 5 & Propionic acid & 668 & 1540 & Sweaty/pungent & A & 8 & 8 & 8 & $\mathrm{MS} / \mathrm{RI} / \mathrm{O} / \mathrm{ST}$ \\
\hline 6 & Butanoic acid & 718 & 1619 & Sweaty & A & 16 & 64 & 64 & $\mathrm{MS} / \mathrm{RI} / \mathrm{O} / \mathrm{ST}$ \\
\hline 7 & Acetoin & 720 & 1275 & Buttery & NB & 16 & 128 & 128 & MS/RI/O/ST \\
\hline 8 & 3-Methyl butanol & 769 & 1067 & Malty & NB & 32 & 32 & 32 & MS/RI/O/ST \\
\hline 9 & 2,3-Hexanedione & 792 & ND & ND & NB & ND & ND & ND & MS/RI/ST \\
\hline 10 & Furfural & 826 & 1457 & Bread-like & NB & 16 & 16 & 16 & $\mathrm{MS} / \mathrm{RI} / \mathrm{O} / \mathrm{ST}$ \\
\hline 11 & 2-Methyl pyrazine & 827 & 1298 & Nutty, roasty & NB & 32 & 32 & 32 & $\mathrm{MS} / \mathrm{RI} / \mathrm{O} / \mathrm{ST}$ \\
\hline 12 & 2/3-Methylbutanoic acid & 831 & 1661 & Sweaty & A & 16 & 64 & 128 & MS/RI/O/ST \\
\hline 13 & Isoamyl acetate & 878 & 1124 & Fruity & NB & 8 & 16 & 16 & $\mathrm{MS} / \mathrm{RI} / \mathrm{O} / \mathrm{ST}$ \\
\hline 14 & 2-Heptanone & 889 & 1182 & ND & NB & ND & ND & ND & MS/RI/ST \\
\hline 15 & Heptanol & 896 & 1174 & Citrusy & NB & 2 & 4 & 8 & MS/RI/O/ST \\
\hline 16 & Methional & 919 & 1449 & Baked potato & NB & 256 & 256 & 256 & $\mathrm{MS} / \mathrm{RI} / \mathrm{O} / \mathrm{ST}$ \\
\hline 17 & 2-Acetyl-1-pyrroline & 922 & 1331 & Roasty & NB & 256 & 256 & 256 & MS/RI/O/ST \\
\hline 18 & Benzaldehyde & 936 & 1196 & Almond-like & NB & 16 & 32 & 32 & $\mathrm{MS} / \mathrm{RI} / \mathrm{O} / \mathrm{ST}$ \\
\hline 19 & 5-Methyl-2-furanmethanol & 953 & 1723 & Bread like & NB & 8 & 8 & 8 & $\mathrm{MS} / \mathrm{RI} / \mathrm{O} / \mathrm{ST}$ \\
\hline 20 & (Z)-4-Heptenal & 960 & 1287 & Biscuit-like & NB & 8 & 16 & 32 & $\mathrm{MS} / \mathrm{RI} / \mathrm{O} / \mathrm{ST}$ \\
\hline 21 & Hexanoic acid & 961 & 1842 & Sweaty & A & 4 & 8 & 8 & MS/RI/O/ST \\
\hline 22 & 1-Heptanol & 970 & ND & ND & NB & ND & ND & ND & MS/RI/ST \\
\hline 23 & 1-Octen-3-one & 971 & 1297 & Mushroom-like & NB & 2 & 4 & 4 & $\mathrm{MS} / \mathrm{RI} / \mathrm{O} / \mathrm{ST}$ \\
\hline 24 & 2,3,5-Trimethylpyrazine & 985 & 1395 & Broth-like & NB & 2 & 4 & 4 & $\mathrm{MS} / \mathrm{RI} / \mathrm{O} / \mathrm{ST}$ \\
\hline 25 & 2-Pentyl furan & 992 & ND & Fruity, sweet & NB & 4 & 4 & 8 & $\mathrm{MS} / \mathrm{RI} / \mathrm{O} / \mathrm{ST}$ \\
\hline 26 & Acetyl pyrazine & 1020 & 1662 & Toast & NB & 16 & 16 & 32 & $\mathrm{MS} / \mathrm{RI} / \mathrm{O} / \mathrm{ST}$ \\
\hline 27 & 4-Hydroxy-2,5-dimethyl-3(2H)-furanone & 1022 & 2038 & Sweet/caramel & A & 128 & 512 & 1024 & $\mathrm{MS} / \mathrm{RI} / \mathrm{O} / \mathrm{ST}$ \\
\hline 28 & Benzyl alcohol & 1039 & 1866 & Sweet/flowery & NB & 8 & 16 & 16 & $\mathrm{MS} / \mathrm{RI} / \mathrm{O} / \mathrm{ST}$ \\
\hline 29 & Phenyl acetaldehyde & 1042 & 1653 & Honey, rose & NB & 16 & 16 & 16 & MS/RI/O/ST \\
\hline 30 & Heptanoic acid & 1077 & 1949 & Rancid & A & 2 & 8 & 8 & $\mathrm{MS} / \mathrm{RI} / \mathrm{O} / \mathrm{ST}$ \\
\hline 31 & 2-Phenyl ethanol & 1136 & 1911 & Honey-like & NB & 16 & 16 & 16 & MS/RI/O/ST \\
\hline 32 & (E)-2-Nonenal & 1164 & 1568 & Fatty, green & NB & 8 & 8 & 8 & $\mathrm{MS} / \mathrm{RI} / \mathrm{O} / \mathrm{ST}$ \\
\hline 33 & Octanoic acid & 1182 & 2047 & Fatty, soapy & A & 16 & 32 & 32 & $\mathrm{MS} / \mathrm{RI} / \mathrm{O} / \mathrm{ST}$ \\
\hline 34 & Ethyl octanoate & 1194 & 1428 & Fruity, fatty & NB & 8 & 8 & 8 & $\mathrm{MS} / \mathrm{RI} / \mathrm{O} / \mathrm{ST}$ \\
\hline 35 & Decanol & 1269 & ND & Fatty & NB & 4 & 8 & 8 & MS/RI/O/ST \\
\hline 36 & Ethyl nonanoate & 1296 & ND & Fruity, tropical & NB & 4 & 4 & 4 & MS/RI/O/ST \\
\hline 37 & $(E, E)-2,4-D e c a d i e n a l$ & 1313 & 1684 & Fatty & NB & 2 & 4 & 8 & MS/RI/O/ST \\
\hline 38 & 4-Vinyl-2-methoxyphenol & 1317 & 2174 & Smoky & A & 16 & 32 & 32 & $\mathrm{MS} / \mathrm{RI} / \mathrm{O} / \mathrm{ST}$ \\
\hline 39 & 4,5-Epoxy-(E)-2-decenal & 1360 & 1970 & Metallic & NB & 4 & 8 & 8 & $\mathrm{MS} / \mathrm{RI} / \mathrm{O} / \mathrm{ST}$ \\
\hline 40 & Vanillin & 1410 & 2601 & Vanilla-like & A & 256 & 256 & 256 & MS/RI/O/ST \\
\hline
\end{tabular}

$N D$ not detected, $C B$ control bagel, $B F_{24} 24 \mathrm{~h}$ fermented bagel, $B F_{48} 48 \mathrm{~h}$ fermented bagel, $N B$ neutral basic fraction, $A$ acidic fraction

a Compound identified by comparison of its odour quality and intensity, retention indices on capillaries DB- 5 and FFAP as well as mass spectra in El with data of reference compounds. MS, RI, O, ST represents mass spectra, retention indices, olfactometry and standard odorants respectively

b Odour quality as perceived at the sniffing port

Aroma-active compounds in long, cold fermented bagels Application of long, cold fermentation $\left(5{ }^{\circ} \mathrm{C}, 24 \mathrm{~h}\right.$ and $48 \mathrm{~h}$ ) produced bagels that exhibited a wider range of
FD factors (4-1024) than the control bagel (Table 2). For instance, the FD factor of 2,3-butanedione in the $24 \mathrm{~h}$ and $48 \mathrm{~h}$ fermented bagels increased by almost (4 times) 


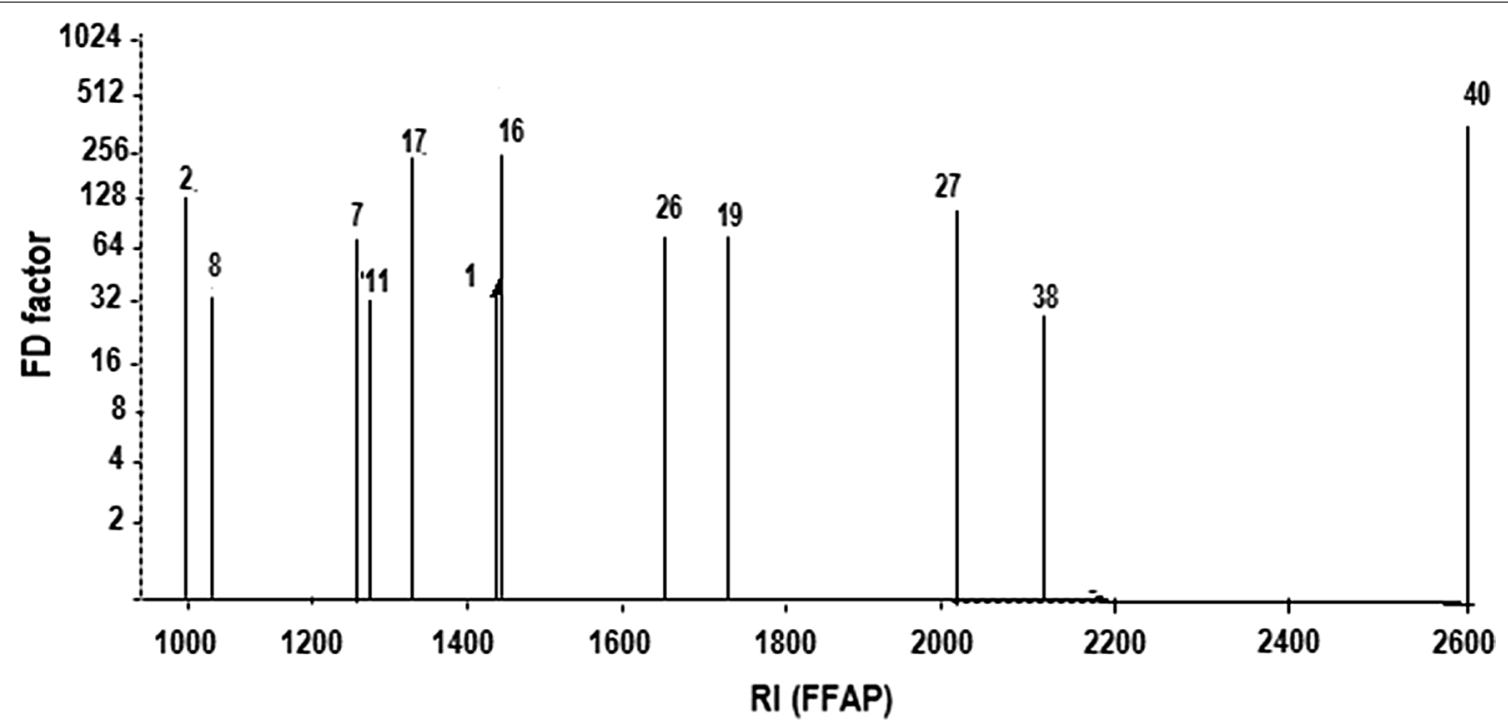

Fig. 2 Flavour dilution chromatogram obtained by the application of AEDA on a distillate of unfermented bagel (control). Compounds with an FD factor $\geq 32$ are displayed. Numbering is identical with that in Table 2

and 8 times the value obtained in the control bagel. Other compounds exhibiting higher FD factors in the long, cold fermented bagels were; acetic acid (sweaty), 2/3-methylbutanal (malty), 2,3-butanedione (buttery), propionic acid (sweaty/pungent), butanoic acid (sweaty), acetoin (buttery), 3-methylbutanol (malty), furfural (bread-like), 2-methyl pyrazine (nutty), 2/3-methyl butanoic acid (sweaty), methional (baked potato-like), 2-acetyl-1-pyrroline (roasty), benzaldehyde (almond-like), (Z)-4-heptenal (biscuit-like), acetyl-pyrazine (toasty), 4-HDMF (sweet/caramel), benzyl alcohol (sweet/flowery), phenyl acetaldehyde (rose-like), 2-phenyl ethanol (honey-like), octanoic acid (fatty), 4-vinyl-2-methoxyphenol (smoky) and vanillin (vanilla-like) all of which exhibited FD factors from 16 to 1024 . While long, cold fermented bagels generally exhibited higher FD values than the control, the $48 \mathrm{~h}$ bagel also showed higher FD values in some compounds (i.e. diacetyl, 1-butanol, 2/3-methylbutanoic acid, heptanol, (Z)-4-heptenal and 2-pentyl furan) compared to the $24 \mathrm{~h}$ bagels.

The influence of fermentation temperatures on the formation of volatile compounds in bread crust and crumb has been well documented [47-49]. While high fermentation temperatures $\left(\geq 27^{\circ} \mathrm{C}\right)$ are more suitable for generating more complete volatile profiles, most bread industries are more favorable to employing longer fermentation time or using sourdough that needs time to ferment. For instance, Zehentbauer and Grosch [48] observed that when bread is prepared from dough subjected to an initial $2 \mathrm{~h}$ of fermentation at $22{ }^{\circ} \mathrm{C}$ and an additional $18 \mathrm{~h}$ of fermentation at $4{ }^{\circ} \mathrm{C}$, the resulting bread exhibited similar amounts of Strecker aldehydes (i.e. 2-methylpropanal, 2-methylbutanal and 3-methylbutanal) as obtained with the artisanal process. This observation is probably due to a longer proteolysis which leads to the formation of amino acids that participates in the Strecker reactions as well as the Ehrlich pathway to produce the aldehydes. It is worthy of note that both 2,3-butanedione and HDMF which exhibited the highest FD factors in the cold fermented bagels as well as many other key aroma compounds such as: 2/3-methylbutanal, acetoin, 3-methylbutanol, furfural, 2-methyl pyrazine, isoamyl acetate, methional, 2-acetyl-1-pyrroline, benzaldehyde, (Z)-4-heptenal, acetyl pyrazine, phenyl acetaldehyde and vanillin have been identified in the crumb of wheat bread [3, 11, 47]. Also, various acids such as acetic acid, butanoic acid, 2/3-methyl butanoic acid and octanoic acid which exhibited high FD factors $\geq 16$ in the cold fermented bagels have been reported in bread $[50,51]$.

\section{Quantitation and odour-activity values (OAVs) of aroma-active compounds in bagels}

To have an insight into the contribution of each compounds to the overall aroma of bagels, 22 aroma-active compounds with FD factors $\geq 16$ were selected for further investigation. For each of the selected compound, a stable isotopologue (Table 1) was employed as an internal standard to quantify it. As expected the long cold fermented bagels produced compounds with significantly $(\mathrm{p}<0.05)$ high concentrations (Table 3$)$. The highest concentrations $\left(1126-12,950 \mu \mathrm{g} \mathrm{kg}{ }^{-1}\right)$ were determined for 2,3-butanedione, 2-phenylethanol, 
Table 3 Concentrations, odour thresholds and odour activity values (OAVs) of key aroma compounds (FD factor $\geq 16$ ) in cold fermented bagels

\begin{tabular}{|c|c|c|c|c|c|c|c|c|}
\hline \multirow[t]{2}{*}{ No. } & \multirow[t]{2}{*}{ Compounds } & \multicolumn{3}{|c|}{ Concentration $\left(\mathrm{\mu g} \mathrm{kg}^{-1}\right)$} & \multirow[t]{2}{*}{$\begin{array}{l}\text { Threshold in } \\
\text { starch }\left(\mu \mathrm{kg}^{-1}\right)\end{array}$} & \multicolumn{3}{|c|}{$\begin{array}{l}\text { Odour activity values } \\
(\mathrm{OAVs})^{c}\end{array}$} \\
\hline & & $\mathrm{CB}$ & $\mathrm{BF}_{24}$ & $\mathrm{BF}_{48}$ & & $\mathrm{CB}$ & $\mathrm{BF}_{24}$ & $\mathrm{BF}_{48}$ \\
\hline 1 & Acetic acid & $300 \pm 2.0^{c}$ & $480 \pm 2.0^{b}$ & $510 \pm 2.0^{\mathrm{a}}$ & 31,140 & $<1$ & $<1$ & $<1$ \\
\hline 2 & 2,3-Butanedione (diacetyl) & $710 \pm 5.1^{c}$ & $11,800 \pm 12.0^{b}$ & $12,950 \pm 15.5^{\mathrm{a}}$ & 6.5 & 109 & 1815 & 1992 \\
\hline 3 & 2/3-Methyl butanal & $164 \pm 2.1^{c}$ & $321 \pm 2.1^{b}$ & $434 \pm 2.0^{\mathrm{a}}$ & $32^{\mathrm{a}}$ & 5 & 10 & 14 \\
\hline 4 & Butanoic acid & $113 \pm 1.0^{c}$ & $201 \pm 1.0^{b}$ & $317 \pm 1.0^{\mathrm{a}}$ & $100^{\mathrm{a}}$ & 1 & 2 & 3 \\
\hline 5 & Acetoin & $1140 \pm 4.5^{c}$ & $1245 \pm 5.0^{b}$ & $1276 \pm 4.0^{\mathrm{a}}$ & $\mathrm{Nf}$ & nd & nd & nd \\
\hline 6 & 3-Methyl butanol & $647 \pm 3.1^{c}$ & $1126 \pm 7.8^{b}$ & $1364 \pm 10.0^{\mathrm{a}}$ & 102 & 6 & 11 & 13 \\
\hline 7 & Furfural & $101 \pm 1.0^{\mathrm{b}}$ & $126 \pm 1.0^{\mathrm{a}}$ & $124 \pm 1.0^{\mathrm{a}}$ & $\mathrm{Nf}$ & nd & nd & nd \\
\hline 8 & 2-Methylpyrazine & $30 \pm 0.2^{c}$ & $54 \pm 0.2^{b}$ & $76 \pm 0.2^{\mathrm{a}}$ & $\mathrm{Nf}$ & nd & nd & nd \\
\hline 9 & 3-Methylbutanoic acid & $64 \pm 1.0^{c}$ & $276 \pm 2.1^{b}$ & $314 \pm 2.0^{\mathrm{a}}$ & 24 & 3 & 12 & 13 \\
\hline 10 & Methional & $16 \pm 0.1^{c}$ & $24 \pm 0.1^{b}$ & $43 \pm 0.1^{a}$ & 0.27 & 59 & 89 & 160 \\
\hline 11 & 2-Acetyl-1-pyrroline & $17 \pm 0.1^{\mathrm{ab}}$ & $19 \pm 0.1^{\mathrm{a}}$ & $18 \pm 0.1^{\mathrm{a}}$ & $0.0073^{\mathrm{a}}$ & 2329 & 2603 & 2466 \\
\hline 12 & Benzaldehyde & $174 \pm 3.0^{c}$ & $920 \pm 4.5^{b}$ & $1121 \pm 6.0^{\mathrm{a}}$ & 350 & $<1$ & 3 & 3 \\
\hline 13 & 5-Methyl-2-furanmethanol & $46 \pm 0.1^{c}$ & $52 \pm 0.1^{b}$ & $58 \pm 0.1^{\mathrm{a}}$ & $11.9^{b}$ & 4 & 4 & 5 \\
\hline 14 & (Z)-4-Heptenal & $51 \pm 0.1^{c}$ & $135 \pm 0.2^{b}$ & $234 \pm 0.2^{\mathrm{a}}$ & 3 & 17 & 45 & 78 \\
\hline 15 & Acetyl pyrazine & $171 \pm 1.0^{c}$ & $186 \pm 1.0^{b}$ & $193 \pm 1.0^{\mathrm{a}}$ & $\mathrm{nf}$ & nd & nd & nd \\
\hline 16 & 4-Hydroxy-2,5-dimethyl-3(2H)-furanone & $234 \pm 2.0^{c}$ & $347 \pm 2.1^{b}$ & $453 \pm 3.0^{\mathrm{a}}$ & $13^{b}$ & 18 & 27 & 35 \\
\hline 17 & Benzyl alcohol & $115 \pm 1.0^{c}$ & $176 \pm 2.0^{b}$ & $182 \pm 2.1^{\mathrm{a}}$ & $\mathrm{nf}$ & nd & nd & nd \\
\hline 18 & Phenyl acetaldehyde & $15 \pm 0.0^{b}$ & $18 \pm 0.1^{\mathrm{a}}$ & $17 \pm 0.1^{\mathrm{a}}$ & $28^{\mathrm{b}}$ & $<1$ & $<1$ & $<1$ \\
\hline 19 & 2-Phenyl ethanol & $1101 \pm 5.0^{c}$ & $1134 \pm 5.0^{b}$ & $1512 \pm 5.0^{\mathrm{a}}$ & $125^{\mathrm{b}}$ & 9 & 9 & 12 \\
\hline 20 & Octanoic acid & $87 \pm 2.1^{c}$ & $102 \pm 2.0^{b}$ & $116 \pm 2.0^{\mathrm{a}}$ & $\mathrm{Nf}$ & nd & nd & nd \\
\hline 21 & 4-Vinyl-2-methoxyphenol & $146 \pm 2.0^{c}$ & $305 \pm 2.1^{\mathrm{b}}$ & $512 \pm 4.0^{\mathrm{a}}$ & $18^{\mathrm{b}}$ & 8 & 17 & 28 \\
\hline 22 & Vanillin & $56 \pm 0.1^{c}$ & $73 \pm 0.1^{b}$ & $95 \pm 0.1^{\mathrm{a}}$ & $4.6^{b}$ & 12 & 16 & 21 \\
\hline
\end{tabular}

$n f$ not found, $n d$ not determined, $C B$ control bagel, $B F_{24} 24 \mathrm{~h}$ fermented bagels, $B F_{48} 48 \mathrm{~h}$ fermented bagels; Mean $\pm \mathrm{SD}$; superscripts with different letters in a row are significantly $(p<0.05)$ different

a Reference; Zehentbauer and Grosch [48]

b Reference; Rychlik and Grosch [10]

c OAV on the basis of odour thresholds in starch

3-methylbutanal and acetoin respectively (Table 3 ). The lowest concentrations $(17-43 \mu \mathrm{g} \mathrm{kg}$ ) were obtained for phenyl acetaldehyde, methional and 2-acetyl-1-pyrroline respectively. A comparative analysis of the aroma potencies between the three differently produced bagels revealed some differences. Cold fermented bagels showed more potencies for the buttery smelling 2,3-butanedione, baked potato-like methional and the toasty-like 2-acetyl-1-pyrroline as revealed by their respective high odour-activity values (Table 3). For example, 2-acetyl-1-pyrroline exceeded its threshold by factors of 2603 and 2466 in the $24 \mathrm{~h}$ and $48 \mathrm{~h}$ cold fermented bagels respectively. 2-Acetyl-1-pyrroline only exceeded its threshold by a factor of 2329 in the control bagels. Similarly, 2,3-butanedione exceeded its threshold by factors of 1815 and 1992 in the $24 \mathrm{~h}$ and $48 \mathrm{~h}$ cold fermented bagels respectively. On the other hand 2,3-butanedione only exceeded its threshold by a factor of 109 in the control bagel. Similar trend was noticed with the methional, acetyl pyrazine, HDMF, 4-vinyl-2-methoxyphenol, vanillin, 2/3-methylbutanal, 2-phenyl ethanol, butanoic acid, 3-methylbutanol and benzaldehyde. However, acetic acid, phenyl acetaldehyde had OAVs below 1.

While some of the bagel aroma compounds were already present in the wheat flour and were thus transferred into the bagel. Others such as 3-methylbutanol, 2-phenyl ethanol and 2,3-butanedione were probably formed during biochemical reactions in the yeast metabolism during the dough fermentation [27]. On the other hand the nitrogen-containing compounds such as the roasty 2-acetyl-1-pyrroline and acetyl pyrazine were formed via the reaction of free amino acids L-ornithine or L-proline with dihydroxyacetone phosphate [52]. In addition to the nitrogen-containing compounds, aldehydes, such as 2/3-methylbutanal (malty), phenyl acetaldehyde (rose/floral) and methional (baked potato-like) were formed by the Strecker degradation of valine, isoleucine, 
leucine, phenylalanine and methionine respectively [53]. Moreover the caramel-like 4-Hydroxy-2,5-dimethyl$3(2 \mathrm{H})$-furanone (HDMF) can be formed by the Maillard reaction [54]. 4-Hydroxy-2,5-dimethyl-3(2H)-furanone is mainly formed via Maillard reaction of pentoses with the amino acids glycine and alanine, respectively. Alternatively, 4-hydroxy-2,5-dimethyl-3(2H)-furanone can also be produced without the direct interaction of glycine [36]. Furthermore, certain aldehydes such as $(E, E)$-2,4-decadienal, (E)-2-nonenal, and $(E)$-4,5-epoxy$(E)$-2-decenal were formed by autoxidation and thermal degradation of fatty acids respectively [53].

\section{Sensory analysis and aroma reconstitution evaluation}

The results of sensory evaluation of the different bagels (i.e. control, $24 \mathrm{~h}$ fermented and $48 \mathrm{~h}$ fermented) are shown in (Fig. 3a, Table 4). In order to select the final descriptors, all the panelists had to achieve complete agreement on any given descriptor for such descriptor to be chosen. The aroma profiles of the cold fermented bagels were characterized as roasty, biscuit-like, malty, smoky and buttery. The control bagel exhibited similar but less intense aroma notes as compared to the cold fermented bagels. However, the $24 \mathrm{~h}$ and $48 \mathrm{~h}$ bagels flavor profiles were similar with the exception of the biscuit-like aroma note (Table 4). The statistical analysis results (Table 4) showed that the six attributes (roasty, malty, buttery, biscuit-like, smoky and baked potato like) with different superscripts provided a clearer explanation of the aroma characteristics of the different bagels. To confirm this observation, recombination experiments were carried out by mixing solutions of the pure reference compounds in the same amounts as indicated for both $24 \mathrm{~h}$ and $48 \mathrm{~h}$ bagels respectively

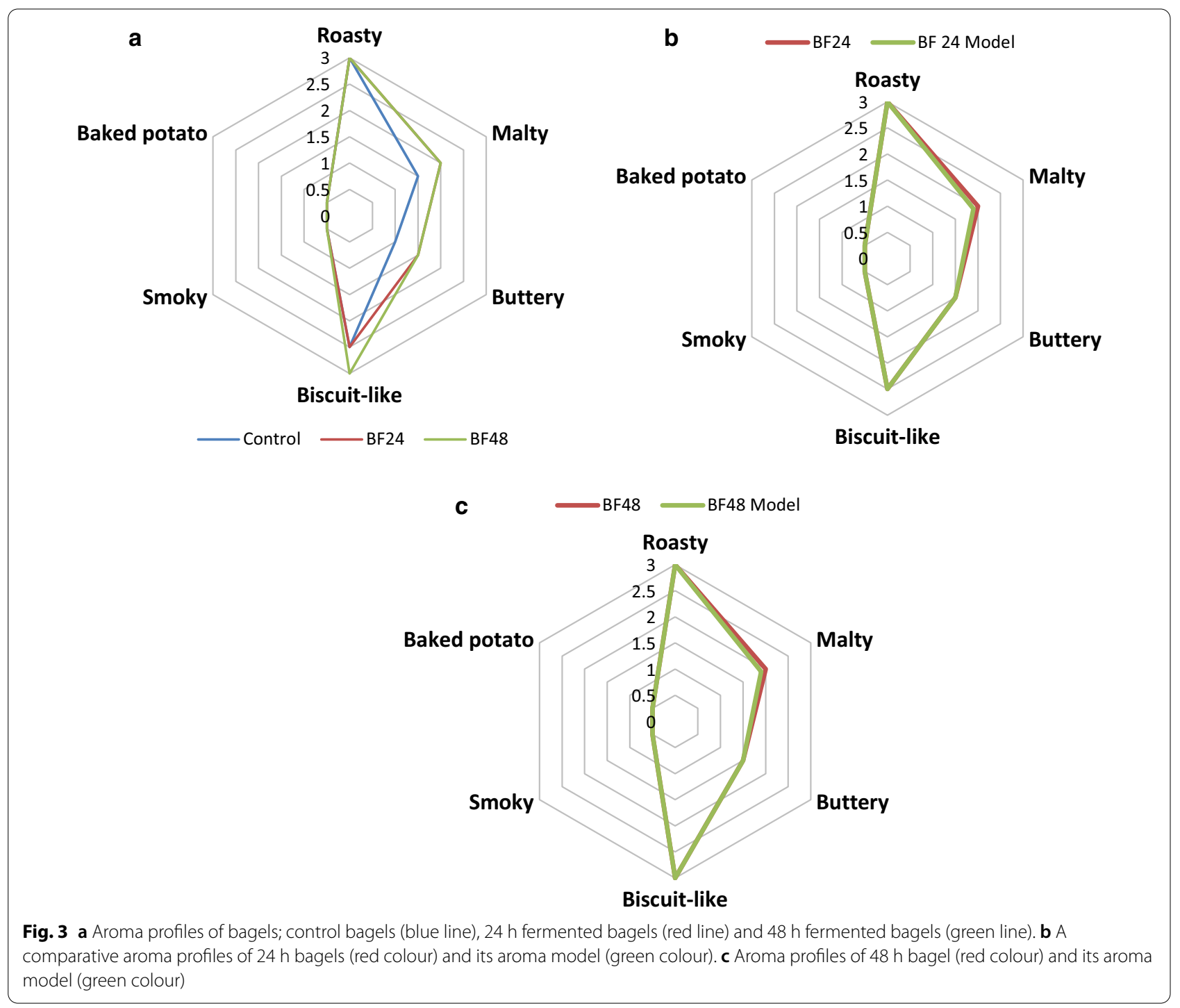


Table 4 The mean scores of the six attributes for the three bagels and the aroma models generated. (Supplementary)

\begin{tabular}{|c|c|c|c|c|c|c|c|}
\hline \multirow[t]{2}{*}{ Sensory attribute } & \multicolumn{3}{|l|}{ Bagels } & \multicolumn{4}{|c|}{ Mean scores of bagel's and their aroma models } \\
\hline & Control & $\mathrm{BF}_{24}$ & $\mathrm{BF}_{48}$ & $\mathrm{BF}_{24}$ & $\mathrm{BF}_{24}$ Model & $\mathrm{BF}_{48}$ & $\mathrm{BF}_{48}$ Model \\
\hline Roasty & $3.0 \pm 0.21^{\mathrm{A}}$ & $3.0 \pm 0.70^{\mathrm{A}}$ & $3.0 \pm 0.91^{\mathrm{A}}$ & $3.0 \pm 0.42^{\mathrm{a}}$ & $3.0 \pm 0.50^{\mathrm{a}}$ & $3.0 \pm 0.72^{\mathrm{a}}$ & $3.0 \pm 0.23^{\mathrm{a}}$ \\
\hline Malty & $1.5 \pm 0.05^{B}$ & $2.0 \pm 0.23^{\mathrm{A}}$ & $2.0 \pm 0.60^{A}$ & $2.0 \pm 0.23^{\mathrm{a}}$ & $1.9 \pm 0.14^{\mathrm{a}}$ & $2.0 \pm 0.33^{\mathrm{a}}$ & $1.9 \pm 0.24^{\mathrm{a}}$ \\
\hline Buttery & $1.0 \pm 0.04^{B}$ & $1.5 \pm 0.02^{\mathrm{A}}$ & $1.5 \pm 0.13^{\mathrm{A}}$ & $1.5 \pm 0.05^{\mathrm{a}}$ & $1.5 \pm 0.25^{\mathrm{a}}$ & $1.5 \pm 0.15^{\mathrm{a}}$ & $1.5 \pm 0.21^{\mathrm{a}}$ \\
\hline Biscuit-like & $2.5 \pm 0.81^{B}$ & $2.5 \pm 0.33^{B}$ & $3.0 \pm 0.56^{\mathrm{A}}$ & $2.5 \pm 0.50^{\mathrm{a}}$ & $2.5 \pm 0.71^{\mathrm{a}}$ & $3.0 \pm 0.30^{\mathrm{a}}$ & $3.0 \pm 0.80^{\mathrm{a}}$ \\
\hline Smoky & $0.5 \pm 0.02^{\mathrm{A}}$ & $0.5 \pm 0.01^{\mathrm{A}}$ & $0.5 \pm 0.03^{\mathrm{A}}$ & $0.5 \pm 0.04^{\mathrm{a}}$ & $0.5 \pm 0.12^{\mathrm{a}}$ & $0.5 \pm 0.03^{\mathrm{a}}$ & $0.5 \pm 0.05^{a}$ \\
\hline Baked potato & $0.5 \pm 0.01^{\mathrm{A}}$ & $0.5 \pm 0.03^{A}$ & $0.5 \pm 0.01^{A}$ & $0.5 \pm 0.02^{a}$ & $0.5 \pm 0.04^{a}$ & $0.5 \pm 0.01^{a}$ & $0.5 \pm 0.03^{a}$ \\
\hline
\end{tabular}

$\bar{A}, B, C: a, b, c$ Different letters within the same row represents significant differences $(p<0.05)$ using Duncan's multiple comparison test $(n=30,10$ panellists with 3 replications)

$\mathrm{BF}_{24} 24 \mathrm{~h}$ fermented bagel, $B F_{48} 48 \mathrm{~h}$ fermented bagel

(Table 5). A parallel evaluation of the recombination models of the freshly baked $24 \mathrm{~h}$ and $48 \mathrm{~h}$ bagels was conducted. Results showed that the recombinant model imitated well the flavor of the freshly baked bagels (Fig. 3b, c, Table 4). The aroma of the recombination models had good similarities for all the odor notes such as roasty, baked potato-like, smoky and biscuit-like. The roasty and biscuit-like aroma notes were perceived as equally intense in the aroma models as well as in the bagels.

Table 5 Aroma models composition for bagels produced from 24 and 48 h cold fermentation

\begin{tabular}{llrr}
\hline No. & Compounds & \multicolumn{2}{c}{$\begin{array}{c}\text { Concentration } \\
\left.\mathrm{kg}^{-1}\right)\end{array}$} \\
\cline { 3 - 4 } & & $\mathrm{BF}_{24}$ & \multicolumn{1}{c}{$\mathrm{BF}_{48}$} \\
\hline 1 & Acetic acid & 480 & 510 \\
2 & 2,3-Butanedione (diacetyl) & 11,800 & 12,950 \\
3 & 2/3-Methyl butanal & 321 & 434 \\
4 & Butanoic acid & 201 & 317 \\
5 & Acetoin & \\
6 & 3-Methyl butanol & 1245 & 1276 \\
7 & 3-Methylbutanoic acid & 1126 & 1364 \\
8 & Methional & 276 & 314 \\
9 & 2-Acetyl-1-pyrroline & 24 & 43 \\
10 & Benzaldehyde & 19 & 18 \\
11 & 5-Methyl-2-furanmethanol & 920 & 1121 \\
12 & (Z)-4-Heptenal & 52 & 58 \\
13 & 4-Hydroxy-2,5-dimethyl-3(2H)-furanone & 347 & 234 \\
14 & Phenyl acetaldehyde & 18 & 453 \\
15 & 2-Phenyl ethanol & 1134 & 1512 \\
16 & 4-Vinyl-2-methoxyphenol & 305 & 512 \\
17 & Vanillin & 73 & 95 \\
\hline
\end{tabular}

a Acetoin was included in the model even though its threshold in starch was not found

b Ethanolic solutions of aroma compounds dissolved in free corn starch

\section{Omission tests}

The contributions of some key aroma compounds to the flavor of the bagels, was evaluated by omission tests. Omission tests are used to assess the contribution of individual compound to the overall aroma of a given food [54]. Eleven aroma omission models (M1-M11), containing either single or a group of compounds, were prepared. Each of the omission models was analyzed in triangular experiments with two complete recombination models (Table 6). Results showed that, the omission of the entire group of acids (M1) from the complete recombination model could be distinguished by 9 out of the 10 assessors. This shows that these acids (i.e. acetic acid, butanoic acid and 3-methyl butanoic acid) play an important role in the overall aroma of the long, cold fermented bagels. In the second group, the ketones (2,3-butanedione and acetoin) with characteristic buttery nuance were omitted. Acetoin was included in this group because of its high concentration. Result of the omission of the entire ketones from the complete recombination model showed that all 10 assessors could detect between the omission model and the complete recombination models. This shows that 2,3-butanedione and acetoin greatly influence the overall aroma of the bagel. When the aldehydes (M3) (2,3-methyl butanal, methional, benzaldehyde, (Z)4-heptenal, phenyl acetaldehyde and vanillin) were omitted, only 8 assessors were able to detect the difference $(\mathrm{p}<0.01)$. Similar trend was observed when the entire group of alcohols (M4) was omitted. In model 5, 4-vinyl-2-methoxyphenol was omitted because of its high concentration and the result showed that only 7 assessors were able to detect the difference between the omission model and the complete recombination models. In model 6, 4-hydroxy-2,5-dimethyl-3(2H)furanone was omitted and this resulted in significant $(p \leq 0.001)$ reduction in the characteristic aroma of the bagels. In addition, 9 of the assessors were able to 
Table 6 Omission analysis on the bagel aroma models $\left(\mathrm{BF}_{24}\right.$ and $\left.\mathrm{BF}_{48}\right)$

\begin{tabular}{|c|c|c|c|c|c|}
\hline Odorant groups & Aroma note & Compounds omitted & $\begin{array}{l}\text { No of correct } \\
\text { judgments } \\
\mathrm{BF}_{24}\end{array}$ & $\begin{array}{l}\text { No of correct } \\
\text { judgments } \\
\mathrm{BF}_{48}\end{array}$ & Significance ${ }^{b}$ \\
\hline Acids (M1) & Sweaty & Acetic acid, butanoic acid, 3-methylbutanoic acid & $9 / 10$ & $9 / 10$ & $* * *$ \\
\hline Ketones (M2) & Buttery & 2,3-Butanedione, acetoin & $10 / 10$ & $10 / 10$ & $* * *$ \\
\hline Acetaldehydes (M3) & $\begin{array}{l}\text { Malty, baked potato, } \\
\text { almond-like, biscuit-like, } \\
\text { vanilla }\end{array}$ & $\begin{array}{l}\text { 2,3-Methylbutanal, methional, benzaldehyde, (Z)-4-hep- } \\
\text { tenal, phenyl acetaldehyde, vanillin }\end{array}$ & $8 / 10$ & $8 / 10$ & $* *$ \\
\hline Alcohols (M4) & Malty, bread-like, honey & $\begin{array}{l}\text { 3-Methylbutanol, 5-methyl-2-furanmethanol, 2-phenyl } \\
\text { ethanol }\end{array}$ & $8 / 10$ & $8 / 10$ & ** \\
\hline Phenol (M5) & Smoky & 4-Vinyl-2-methoxyphenol & $7 / 10$ & $7 / 10$ & * \\
\hline (M6) & Sweat, caramel & 4-Hydroxy-2,5-dimethyl-3(2H)-furanone & $9 / 10$ & $9 / 10$ & $* * *$ \\
\hline (M7) & Floral, honey & 2-Phenyl ethanol & $8 / 10$ & $8 / 10$ & $* *$ \\
\hline (M8) & Cooked potato-like & Methional & $8 / 10$ & $8 / 10$ & $* *$ \\
\hline (M9) & Biscuit-like & (Z)-4-Heptenal & $9 / 10$ & $9 / 10$ & $* * *$ \\
\hline (M10) & Bread-like & 5-Methyl-2-furanmethanol & $10 / 10$ & $10 / 10$ & $* * *$ \\
\hline (M11) & Popcorn-like & 2-Acetyl-1-pyrroline & $10 / 10$ & $10 / 10$ & $* * *$ \\
\hline
\end{tabular}

M1-M11 Models

a Number of correct judgments from 10 assessors

b Significance: * significant $(a \leq 0.05)$; ${ }^{* *}$, highly significant $(a \leq 0.01) ;{ }^{* *}$, very highly significant $(a \leq 0.001)$

distinguish its omission from the complete recombination models. Similar observation was obtained when other single compounds such as 2-phenyl ethanol, methional, (Z)-4-heptenal, 5-methyl-2-furanmethanol and 2-acetyl-1-pyrroline were omitted from the complete recombination models respectively. However, the omission of 5-methyl-2-furanmethanol and 2-acetyl1 -pyrroline was detected by all 10 assessors.

\section{Conclusion}

This study has revealed the key aroma-active compounds responsible for the characteristic aroma of the long, cold fermented bagels. The results of the OAVs and sensory studies showed distinct differences in the aroma notes of the cold fermented and control bagels. Whilst the cold fermented bagels exhibited roasty, malty, buttery, baked potato-like, smoky and biscuit-like notes, the odour notes in the control bagels were similar to the other bagels but less intense. Aroma compounds such as 2,3-butanedione (buttery), acetoin (buttery), 2-acetyl1-pyrroline (roasty), 5-methyl-2-furanmethanol (breadlike), (Z)-4-heptenal (biscuit-like) and HDMF, were the key aroma compounds. In addition, vanillin (vanilla), 2/3-methylbutanal (malty), 3-methyl butanoic acid (sweaty), 3-methylbutanol (malty), methional (baked potato-like), 2-phenyl ethanol (honey-like), benzaldehyde (almond-like), and butanoic acid (sweaty) were identified as important aroma compounds of bagels. These finding establishes a basis for further research on the effect of cold fermentation on bakery products found in many world cuisines.

\section{Acknowledgements \\ The authors wish to thank the Faculty of Food Science \& Technology, Univer- sity Putra Malaysia for supplying the facilities for this study. \\ Authors' contributions \\ OL: Conceptualize, funding acquisition, supervised and reviewed the initial and final manuscript. FD, MM, HJ: formal analysis, data collection, writing of draft, AL: reviewed initial draft and provided necessary information on bagel. All authors reviewed the manuscript. All authors read and approved the final manuscript.}

\section{Funding}

Financial support for this research was provided by the University Putra Malaysia research scheme (Grant No. 9478500).

\section{Availability of data and materials}

All data generated or analyzed during this study are included in this published article.

\section{Declarations}

\section{Ethics approval and consent to participate}

The study protocol and consent procedure received ethical approval from the Institutional review board of the University Putra Malaysia. Informed consent was obtained from all individual participants included in the study.

\section{Consent for publication}

Not applicable.

\section{Competing interests}

The authors declare no competing interests.

\section{Author details}

${ }^{1}$ Department of Food Technology, University Putra Malaysia, UPM, 43400 Serdang, Malaysia. ${ }^{2}$ Department of Food Service and Management, University Putra Malaysia, UPM, 43400 Serdang, Malaysia. ${ }^{3}$ Food Science \&Human Nutrition, School of Food \& Agriculture, University of Maine, Orono, ME, USA. 
Received: 21 December 2020 Accepted: 25 February 2021 Published online: 13 March 2021

\section{References}

1. MRI-NHCS (2019) Bagel consumption in America. National consumer study. http://mrisimmons.com/solutions/national-studies. Accessed 9 Mar 2020

2. Aliani M, Ryland D, Pierce GN (2012) Effect of flax addition on the flavor profile and acceptability of bagels. J Food Sci 71:S62-S70

3. Ying S, Lasekan O, Naidu KRM, Lasekan A (2012) Headspace solid-phase Micro extraction gas chromatography-mass spectrometry and gas chromatograph-olfactometry analysis of volatile compounds in pineapple breads. Molecules 17:13795-13812

4. Paraskevopoulos A, Chrysanthou A, Koutidou M (2012) Characterization of volatile compounds of lupin protein isolate-enriched wheat flour bread. Food Res Int 48:568-577

5. Lasekan O, Otto S (2009) In vivo analysis of palm wine (Eaeis guineensis) volatile organic compounds (VOCs) by proton transfer reaction-mass spectrometry. Int J Mass Spectrom 282:45-49

6. Ruiz JA, Quilez J, Mestres M, Guasch J (2003) Solid-phase micro extraction method for headspace analysis of volatile compounds in bread crumb. Cereal Chem 80:255-259

7. Hansen A, Schieberle P (2005) Generation of aroma compounds during sourdough fermentation; Applied and fundamental aspects. Trends Food Sci Technol 16:85-94

8. Moris C, Moris GA (2012) The effect of inulin and fructo-oligosaccharide supplementation on the textural, rheological and sensory properties of bread and their role in weight management-a review. Food Chem 133:237-248

9. Jiang J, Coffey P, Toohey B (1995) Improvement of odour intensity measurement using dynamic olfactometry. J Air Waste Manag Assoc 56:675-683

10. Rychlik M, Grosch W (1996) Identification and quantification of potent odorants formed by toasting of wheat bread. LWT-Food Sci Technol 29:515-525

11. Poinot P, Grua-Priol J, Arviseriet G, Rannou C, Semenou M, Le Bail A, Prost C (2007) Optimization of HS-SPME to study representatives of partially baked bread odorant extracts. Food Res Int 40:1170-1180

12. Ye CW, Zhang XN, Gao YL, Wang YL, Pan SY, Li XJ (2012) Multiple headspace solid-phase micro extraction after matrix modification for avoiding matrix effect in the determination of ethyl carbamate in bread. Anal Chim Acta 710:75-80

13. Engel W, Bahr W, Schieberle P (1996) Solvent assisted flavor evaporationa new and versatile technique for the careful and direct isolation of aroma compounds from complex food matrices. Eur Food Res Technol 209:237-241

14. Sen A, Laskawy G, Schieberle P, Grosch W (1991) Quantitative determination of $\beta$-damascenone in foods using a stable isotope dilution assay. J Agric Food Chem 39:757-759

15. Lasekan O, Hussein F (2018) Classification of different pineapple varieties grown in Malaysia based on volatile fingerprinting and sensory analysis. Chem Cent J 12:140. https://doi.org/10.1186/s13065-018-0505-3

16. Pacynski M, Wojtasiak RZ, Mildner-Szkudlarz S (2015) Improving the aroma of gluten-free bread. LWT-Food Sci Technol 63:706-713

17. Sapirstein HD, Siddhu S, Aliani M (2012) Discrimination of volatiles of refined an whole wheat bread containing red and white wheat bran using an electronic nose. J Food Sci 77:399-406

18. Poinot P, Arvisent G, Grua-Priol J, Fillonneous C, Prost C (2009) Use of an artificial mouth to study bread aroma. Food Res Int 42:717-726

19. Onishi M, Inoue M, Araki T, Iwabuchi H, Sagara Y (2012) A PTR-MS based protocol for stimulating bread aroma during mastication. Food Bioprocess Technol 5:1228-1237

20. Schieberle P, Hofmann T (2012) Mapping the combinatorial code of food flavors by Means of molecular sensory science approach. In: Jelen $\mathrm{H}$ (ed) Chemical and functional properties of food components series. Food flavor, chemical, sensory and technological properties. Boca Raton, CRC Press, pp 413-438
21. Luca N, Mall V, Schieberle P (2019) Characterization of key aroma compounds in a commercial rum and Australian red wine by means of a new sensomics-based expert system (SEBES) — an approach to use Artificial Intelligence in Determining Food Odor Codes. ACS Publ J Agric Food Chem 67(14):4011-4022

22. Sahin B, Schieberle P (2019) Characterization of the key aroma compounds in yeast Dumplings hy means of the sensomics concept. J Agric Food Chem 63:2973-2979

23. Parker JK (2015) Introduction to aroma compounds in foods. In: Flavor development, analysis and perception in food and beverages - a volume in Woodland Publishing Series in Food Science, Technology \& Nutrition, pp 4-30. https://doi.org/10.1016/B978-1-78242-103-0.00001-1

24. Schieberle HT, Schieberle P, Hofmann T (2011) Food flavor. In: Henryk J (ed) CRC Press, Boca Raton, pp 413-438

25. Schoenauer S, Schieberle P (2019) Characterization of the key aroma compounds in the crust of soft pretzels by application of the sensomics concept. J Agric Food Chem 67:7110-7119

26. Schieberle P, Grosch W (1983) Identification of flavorings from the crust of Rye bread. Zeitschrift fur Lebensmittel-Untersuchung und-Forschung 177:173-180

27. Gassenmeier K, Schieberle P (1995) Potent aromatic compounds in the crumb of wheat bread (French-type). Influence of pre-ferments and studies on the formation of key odorants during dough processing. Zeitschrift fur Lebensmittel-Untersuchung und-Forschung 201:241-248

28. Guth H (1997) Identification of character impact odorants of different white wine varieties. J Agric Food Chem 45:3022-3026

29. Schieberle P, Grosch W (1992) Changes in the concentration of potent crust odorants during storage of white bread. Flavor Fragr J 7:213-218

30. Schieberle P, Grosch W (1987) Evaluation of the flavor of wheat and rye bread crusts by aroma extract dilution analysis. Zeitschrift fur Lebensmittel-Untersuchung und-Forschung 185:111-113

31. Schieberle P, Hofmann T (1997) Evaluation of the character impact odorants in fresh strawberry juice by quantitative measurements and sensory studies on model mixtures. J Agric Food Chem 45:227-232

32. Guth H, Grosch W (1994) Identification of the character impact odorants of stewed beef juice by instrumental and sensory studies. J Agric Food Chem 42:2862-2866

33. Czerny M, Grosch W (1993) Quantitation of character-impact odor compounds of roasted beef. Zeitschrift fur Lebensmittel-Untersuchung und-Forschung 196:417-422

34. Poisson L, Schieberle P (2008) Characterization of the key aroma compounds in an American bourbon whisky by quantitative measurements, aroma recombination, and omission studies. J Agric Food Chem 56:5820-5826

35. Guth H, Grosch W (1990) Deterioration of soya-bean oil: Quantitation of primary Flavor compounds using a stable isotope dilution assay. LWTFood Sci Technol 23:513-522

36. Blank I, Fay LB (1996) Formation of 4-hydroxy-2,5-dimethyl-3(2H)furanone and 4-hydroxy-2(or) 5-ethyl (or2)-methyl-3 (2H)-furanone through Maillard reaction based on pentose sugars. J Agric Food Chem 44:531-536

37. Lasekan O, Ng SS (2015) Key volatile aroma compounds of three black velvet tamarind (Dialium) fruit species. Food Chem 168:561-565

38. Greger V, Schieberle P (2007) Characterization of the key aroma compounds in apricots (Prunus armeniaca) by application of the molecular sensory science concept. J Agric Food Chem 55:5221-5228

39. Lasekan O, Yap P (2019) Characterization of the aroma compounds in fresh and dried sapodilla (Manikara zapota) by the application of aroma extracts dilution analysis. CYTA-J Food 16(1):801-806

40. Schieberle P (1995) Recent developments in methods for analysis of flavor compounds and their precursors. In: Gaonkar A (ed) Characterization of food: emerging methods. Elsevier, Amsterdam, pp 403-431

41. Lasekan O, Buettner A, Christlbauer M (2007) Investigation of important odorants of palm wine (Elais quineensis). Food Chem 104:15-23

42. ISO 8589 (2007) Sensory analysis, General guidance for the design of test rooms. International Organization for Standardization, Geneva

43. Steinhaus M, Sinuco D, Polster J, Osorio C, Schieberle P (2009) Characterization of the key aroma compounds in pink guava (Psidium guajava, L) by means of aroma re-engineering experiments and omission tests. J Agric Food Chem 57:2882-2888 
44. Lasekan O, Khatib A, Juhari H, Patiram P, Lasekan A (2013) Headspace solid-phase micro extraction gas chromatography-mass spectrometry determination of volatile compounds in different varieties of African star apple fruit (Chrysophillum albidum). Food Chem 141:2089-2097

45. Callejo MN, Vargas-Kostiuk ME, Rodriguez-Quijand M (2015) Selection, training and validation process of a sensory panel for bread analysis: influence of cultivar on quality of breads made from common wheat and spelt wheat. J Cereal Sci 61:55-62

46. ISO 8589 (2004) Sensory analysis, triangular test. International Organization for Standardization, Geneva

47. Qhairul-Izzreen MNN, Hansen AS, Peteren MA (2016) Volatile compounds in whole meal bread crust: the effects of yeast level and fermentation temperature. Food Chem 210:566-576

48. Zehentbauer G, Grosch W (1998) Crust aroma of baguettes-1. Key odorants of baguettes prepared in two different ways. J Cereal Sci 28:81-92

49. Pico J, Bernal J, Gomez M (2015) Wheat bread aroma compounds in crumb and crust: a review. Food Res Int 75:200-215

50. Frasse P, Lambert S, Richard-Molard D, Chiron H (1993) The influence of fermentation on volatile compounds in French bread dough. LWT-Food Sci Technol 26:126-132
51. Heitmann M, Zannini E, Axel C, Arendt E (2017) Correlation of flavor profile to sensory analysis of bread produced with different Saccharomyces cerevisiae originating from the baking and beverage industry. Cereal Chem 94(4):746-751

52. Matheis K, Granvogl M (2016) Characterization of the key aroma compounds in commercial native cold-pressed rapeseed oil by means of sensomic approach. Eur Food Res Technol 242:1565-1575

53. Erten ES, Cadwallader KR (2017) Identification of predominant aroma components of raw, dry roasted and oil roasted almonds. Food Chem 217:244-253

54. Grosch W (2001) Evaluation of key odorants of foods by dilution experiments, aroma models and omission. Chem Sen 26:533-545

\section{Publisher's Note}

Springer Nature remains neutral with regard to jurisdictional claims in published maps and institutional affiliations.
Ready to submit your research? Choose BMC and benefit from:

- fast, convenient online submission

- thorough peer review by experienced researchers in your field

- rapid publication on acceptance

- support for research data, including large and complex data types

- gold Open Access which fosters wider collaboration and increased citations

- maximum visibility for your research: over $100 \mathrm{M}$ website views per year

At BMC, research is always in progress.

Learn more biomedcentral.com/submissions 